\title{
Three Wishes and Psychological Functioning in Boys with Duchenne Muscular Dystrophy
}

\author{
NANCY E. NEREO, PH.D. \\ Outpatient Psychiatry Department, Children's Hospital and Health Center, University of California, San Diego, California \\ VERONICA J. HINTON, PH.D. \\ G. H. Sergievsky Center and Department of Neurology, College of Physicians and Surgeons, Columbia University, \\ New York, New York
}

\begin{abstract}
This study examined Three Wishes (a projective technique commonly used with children) in boys with Duchenne muscular dystrophy (DMD), a fatal, progressive illness $(n=74)$. A reliable and parsimonious scoring system was developed to code wish type. Probands' responses were compared with unaffected siblings $(n=32)$ and a male comparison group $(n=43)$. Contrary to what was expected, the DMD group did not make significantly more health-related wishes than their siblings or the comparison group. Further, no association between health-related wishes and problem behaviors was observed in the DMD group. These findings indicate that, despite increased stressors, boys with DMD present wishes similar to those of their healthy peers. J Dev Behav Pediatr 24:1-8, 2003. Index terms: Duchenne muscular dystrophy, Three Wishes, psychological functioning.
\end{abstract}

Duchenne muscular dystrophy (DMD), one of the many forms of muscular dystrophy, is a genetic developmental disorder characterized by progressive muscle weakness. The gene involved in DMD is located on the $\mathrm{X}$ chromosome, so boys have the severe, fatal form of the disease. Initially, affected boys appear to be developing normally, but physical difficulty, first noted as clumsiness, becomes increasingly apparent. A definitive diagnosis is usually made at approximately 5 years of age. Over time, muscles continue to weaken, and by adolescence the boys require a wheelchair along with daily physical therapy to maximize muscle function. Often, surgery is required to correct spine curvature that develops as the result of wheelchair use. Death generally occurs by the third decade of life, usually caused by extreme muscle weakness that leads to respiratory or cardiac failure. Approximately 19\% of the boys diagnosed with DMD are also mentally retarded, compared with $2 \%$ to $3 \%$ in the general population. Although many boys with DMD function within normal limits of intellectual functioning, a selective pattern of cognitive deficits has been demonstrated irrespective of IQ level. ${ }^{1,2}$ Currently, there is no cure for DMD, and care efforts are aimed at delaying the progression of the disease and improving quality of life.

Such an illness could be expected to present a number of stressors and affect a child's psychological adjustment. In general, however, there has been a paucity of research

Received December 14, 2001; accepted November 7, 2002.

Address for reprints: Nancy Nereo, Ph.D., Outpatient Psychiatry Department, Children's Hospital and Health Center, 3020 Children's Way MC 5018, San Diego, CA 92123; e-mail: nnereo@chsd.org. regarding psychological functioning in boys with DMD. Early work found that adjustment in boys with DMD, measured by psychological evaluation, was similar to that exhibited by all children, ${ }^{3}$ and that there was a "relative absence of serious emotional illness." 4 In contrast, other research found that boys with DMD had poorer peer relations and exhibited greater social isolation, anxiety, and depression than generally expected. ${ }^{5}$ Similarly, adolescents with DMD were found to exhibit increased social isolation, passivity, and depression. ${ }^{6}$ More recently, Thompson and colleagues found that $87 \%$ of boys with DMD exhibited behavioral problems, primarily in the realm of internalizing behaviors, such as depression. ${ }^{7}$ Work from our research group indicates that boys with DMD exhibit poor social and interpersonal behavior skills. We posit that the social deficit is not a reaction to the disease but rather an associated characteristic, because it is consistently found among boys with DMD, regardless of age or IQ level, unlike psychological correlates of other childhood illnesses. ${ }^{8}$

Past research has predominantly relied on the parent report for assessing children's psychological adjustment. There are many practical reasons for using the parent report; in particular, developing language skills in children are often a limiting factor in eliciting information from them about emotional or psychological issues. In evaluation of child adjustment to chronic, terminal illness, inclusion of a children's self-report measure may also help to provide an accurate picture of functioning. Use of a self-report questionnaire may provide some information about a child; however, direct questions regarding internal experience pose comprehension problems for younger children. A measure that is understandable to children of a wide age range and that provides information about a child's 
psychological state would be useful for accessing a child's emotional experience. Further, a measure that does not require completion of questionnaires or rating scales that may be difficult for children with limited fine motor abilities would be advantageous.

In various clinical settings, children are often asked Three Wishes: "If you could make three wishes, any three wishes in the whole world, what would they be?" Children provide a myriad of responses to this question, for example, to go to Disney World, to have a pet, that they could fly, that they would grow up to be a professional basketball player, and that their parents wouldn't fight so much. From the wishes children provide, clinicians often hypothesize that they have learned something about the child.

Although Three Wishes is often used clinically to gain an understanding of a child's psychological state and personality, scant empirical research of Three Wishes has been conducted since the first studies reported 70 years ago. 9,10 Most of these studies have examined factors related to the presentation of certain wishes, such as age, socioeconomic status, and gender. Generally, these studies have shown that children's wishes become more abstract and less concrete as they grow older. ${ }^{11-15}$ Many early studies found differences across gender, with boys' wishes more materialistic and achievement-oriented and girls' wishes more concerned with interpersonal relations, ${ }^{11,13,16-18}$ although the initial studies did not find gender differences. ${ }^{19,20}$ However, these studies have used different and sometimes inconsistent scoring systems for examining wishes. Moreover, this small body of research spans 70 years, during which time children and researchers' perspectives have changed greatly.

In clinical practice today, Three Wishes is often used with children who have physical or psychological illness. It is commonly believed that Three Wishes of children who are physically ill or exhibit psychiatric symptoms provide a "window" into the child's emotional experience, particularly those wishes that touch on emotional or difficult issues that the child may be experiencing. However, systematic study of wishes to determine whether this is the case has been minimal. Authors of one study examining Three Wishes in children hospitalized for cancer treatment concluded that these children were all preoccupied with making a change in their immediate situation, which was expressed in varying ways according to age: Younger children wished to go home, whereas older children wished to have their disease cured. ${ }^{21}$ These findings indicate that Three Wishes may, in some cases, be useful as an indicator of a child's concerns or internal state. Examination of Three Wishes in children with a physical illness, compared with their siblings and with children who are not affected by illness, may help to elucidate the psychological impact of the chronic illness. In addition, examination of Three Wishes of children with chronic illness as they relate to other child variables may indicate how particular wishes may be related to other psychological aspects of the children.

The present study therefore examined Three Wishes in boys with DMD relative to their siblings and a comparison group of healthy boys. Accordingly, the study aims were as follows:

1. To develop a descriptive and reliable system for coding Three Wishes.

2. To examine Three Wishes of boys with DMD compared with their siblings and a male comparison group. In particular, it was hypothesized that healthrelated wishes would occur more frequently in the DMD group.

3. To examine Three Wishes and its relationship to problem child behaviors in boys with DMD. Specifically, it was hypothesized that health-related wishes presented by children with DMD would be associated with greater problem child behaviors.

\section{METHOD}

\section{Participants}

Data for 74 boys with Duchenne muscular dystrophy (DMD) and 32 siblings of boys with DMD were collected as part of a larger study of cognitive skills in boys with DMD. One sibling per child with DMD was included in the analysis. Inclusion criteria were age between 6 and 12 years, in otherwise good general health, Englishspeaking, willing to participate, and not mentally retarded (estimated Verbal IQ > 70). The group was limited to ages 6 through 12 years to avoid increasing social desirability of responses in adolescence. These participants were recruited through the Duchenne Muscular Dystrophy Clinical Trials Study; private physicians associated with the Muscular Dystrophy Association clinics at Columbia Presbyterian Medical Center and Albert Einstein Medical Center in New York, New York, Scottish Rite Children's Medical Center in Atlanta, Georgia, and Newington Children's Hospital in Newington, Connecticut; and announcements and mailings through the Muscular Dystrophy Association and the Duchenne Parent Project.

All participants with DMD (100\%) were male. The mean age of DMD participants was 9.29 years (SD 1.69, range $6.00-12.75 \mathrm{yr}$ ), and the mean grade in school was 3.22 (SD 1.88, range 1-7). A majority of boys with DMD were white $(86.5 \%)$ with lesser representation from Latino, African-American, Indian, and biracial participants $(5.4 \%, 5.4 \%, 1.4 \%$, and $1.4 \%$, respectively). At the time of assessment, $41.9 \%$ of boys with DMD were using wheelchairs.

The sibling group consisted of 18 males (56.25\%) and 14 females $(43.75 \%)$. Female siblings were included along with male siblings because they share environmental and some biological variables with their brothers, making them appropriate for comparison, and their inclusion creates the largest possible group for stronger analyses. The mean age of sibling participants was 9.23 years (SD 2.24, range $6.08-12.75 \mathrm{yr}$ ), and the mean grade in school was 3.59 (SD 2.39, range $0-8$ ). With regard to ethnicity, $90.3 \%$ of siblings were white, $6.3 \%$ were Latino, and $3.1 \%$ were African-American. 
Because earlier work showed gender effects in wish type, an additional control group of 43 boys was included. These participants were recruited through schools, community groups, and extracurricular organizations in a local school district that consented to recruitment for participation. Along with meeting the inclusion criteria previously listed, these boys did not have a history of illness in their immediate families. The mean age of comparison participants was 9.99 years (SD 1.72, range $6.08-12.58 \mathrm{yr}$ ), and the mean grade in school was 3.93 (SD 1.83, range $0-7)$. A majority of participants were white $(97.7 \%)$ with additional representation from biracial participants $(2.3 \%)$.

\section{Measures}

After obtaining informed consent from parents and assent from participating children, demographic information was collected by written questionnaire, and the following measures were administered:

Children were asked Three Wishes, worded as follows: "If you could make three wishes, any three wishes in the whole world, what would they be?" The examiner noted verbatim the child's response. All wishes were coded according to a concise yet comprehensive system of categories derived from a review of systems used in past research, ${ }^{10,11,13,17-25}$ including a category pertinent to studying children with physical illnesses. Previous systems included as few as two categories (concrete vs abstract) ${ }^{12,14}$ and as many as 27 categories. ${ }^{10}$ The present system was developed with the aims of combining previous systems that were thematically similar or redundant and of maintaining a descriptive and varied set of categories. To aid in understanding how the present system was derived from previous research in Three Wishes, Table 1 summarizes all categories from previous systems and their representation in the present system. Further, this Table illustrates the present system's parsimonious yet descriptive nature. The categories in the current system include (1) Material Goods, (2) Pets/Animals, (3) Activities, (4) Interpersonal/Family, (5) Future/Goal, (6) Personal Attribute, (7) Situational (8) Situational/Health-Related, (9) Altruism, (10) Fantasy, (11) Negative Wishes, (12) No Wishes, and (13) Miscellaneous.

The category of Material Goods includes money and any physical object, such as toys, a big house, a swimming pool, and candy. The wish for Pets is a separate category, because this wish involves an element of relatedness and reciprocity that inanimate objects cannot offer. The category of Activities includes wishes for specific activities not impeded specifically by the child's illness or situation, such as travel, play, and going to a restaurant. Interpersonal/ Family wishes include wishes for social relationships and situations of a general nature, such as a wish to get married, have children, or have a sibling. Future/Goal wishes are wishes for future achievements or situations at any time in the future, such as a wish for educational success or a particular occupation. Personal Attribute wishes include wishes for psychological or physical benefits, such as a wish to be tall or smart. Situational wishes generally reflect a change in a negative personal situation that is specific to the child or the child's environment, excluding those that are related to illness. For example, wishes included in this category are "that my father would find a job" or "that my parents would get back together." Although these wishes may contain interpersonal references, they differ from Interpersonal/Family wishes in that they are specific to the child's particular situation, rather than a general wish for a type of relationship. Situational/Health-Related wishes are similar in that they include wishes that are specific to a child's situation but exclusively related to health or illness, such as wishes for good health or a cure to the illness and wishes to walk. Sibling wishes related either to their brother's illness or to general health were also coded in this category. Altruistic wishes are those that may not have a direct benefit for the child but that benefit the community or the society at large, such as world peace. Fantasy wishes are those that cannot realistically come true, such as seeing a Tyrannosaurus Rex or being able to fly. Negative wishes include wishes for things not to be as they are, such as wishes for no parents. These wishes reflect negative feelings about circumstances that are generally viewed positively or neutrally, or about normal circumstances (such as having parents or going to school). (In contrast, a wish to end circumstances that would be expected to elicit negative feelings, such as being bullied by a classmate, would be coded Situational.) In addition, apparently negative or aggressive wishes, such as "that everyone in school would die," are also coded as Negative. Responses including "I don't know" and "nothing" are coded in the No Wishes category. The Miscellaneous category includes all wishes that cannot be categorized elsewhere, including more wishes.

The Child Behavior Checklist $(\mathrm{CBCL})^{26}$ was completed by parents of the boys with DMD. The CBCL is a widely used measure consisting of 108 problem behaviors. Parents rate, on a 0 (never) to 2 (very much) scale, how often their child engages in each behavior. Using a computer-scoring system, the CBCL yields $t$ scores (mean 50 , SD 10) on eight subscales of behavior and personality, two factors of Internalization and Externalization, and a Total $t$ score. Test-retest reliability for the 108 problem behaviors is $.95 .^{26}$

As an estimate of Verbal IQ, all children were administered the Peabody Picture Vocabulary Test-Revised (PPVT-R) ${ }^{27}$ an individually administered test of receptive vocabulary, yielding age-referenced standard scores (mean 100, SD 15). PPVT-R scores have been shown to have a correlation of .70 with the Weschler Intelligence Scales for Children-Revised Full-Scale IQ score; the correlation is .69 with the Verbal IQ score. ${ }^{28}$

\section{Procedure}

The boys with DMD and their siblings were tested in the hospital where the study was being conducted or in their homes in cases in which travel was inconvenient. The comparison group was tested in a location in the town in which they attend school. In all cases, participants were asked Three Wishes at the beginning of the testing. Parents 
Table 1. Relationship of Present Three Wishes Coding System to Previous Systems

\begin{tabular}{|c|c|c|}
\hline $\begin{array}{l}\text { Current System Category } \\
\text { Material Goods }\end{array}$ & \multicolumn{2}{|c|}{ Previous Literature Categories Included in Current Category } \\
\hline Material Goods & $\begin{array}{l}\text { Specific material objects and possessions }{ }^{10} \\
\text { Good living quarters } \\
\text { Money }^{10,11,17,18,20,23,24} \\
\text { Material }^{22,23,24} \\
\text { To own something }^{21} \\
\text { Material possession }^{11} \\
\text { Possessions }^{13}\end{array}$ & $\begin{array}{l}\text { Toys, sports equipment }{ }^{17} \\
\text { Luxury }^{17} \\
\text { House }^{17} \\
\text { Food/candy }^{17} \\
\text { Clothes }{ }^{17} \\
\text { To have material things }{ }^{25} \\
\text { For toys }{ }^{25} \\
{ }^{*} \text { Possessions/activities } \\
\end{array}$ \\
\hline Pets & Pets ${ }^{11,17,23,24}$ & \\
\hline Activities & $\begin{array}{l}\text { Activities }^{13,23,24} \\
\text { Activities, sports, diversions }{ }^{10} \\
\text { Play } \\
\text { To eat something }^{21}\end{array}$ & $\begin{array}{l}\text { Exercise }^{21} \\
\text { Travel }^{11,17,23} \\
{ }^{*} \text { Possessions/activities }{ }^{18,20}\end{array}$ \\
\hline Interpersonal/Family & $\begin{array}{l}\text { Another person } \\
\text { Social relationship } \\
\text { To be married }^{18} \\
\text { Family }^{23} \\
\text { Have baby, sibling }^{10} \\
\text { Companionship } \\
\text { Co }\end{array}$ & $\begin{array}{l}\text { Siblings }^{17} \\
\text { Marriage }^{17,20} \\
\text { Children }^{17} \\
\text { Persons } \\
\text { Parents never die } \\
\text { Po be married, have a lover }\end{array}$ \\
\hline Future/Goal & $\begin{array}{l}\text { Achievement }{ }^{13} \\
\text { Ambition }^{17} \\
\text { Goal Wishes } \\
\text { Opportunities and accomplishments }{ }^{10}\end{array}$ & $\begin{array}{l}\text { Vacation }{ }^{18,20} \\
\text { Occupational }^{24} \\
\text { To be someone } \\
\text { For vocation } \\
\text { Personal prestige, adventure } \\
\text { Pen }^{10}\end{array}$ \\
\hline Personal/Attribute & $\begin{array}{l}\text { Specific personal skill, attribute, identity }{ }^{11} \\
{ }^{*} \text { Health and Happiness }{ }^{17} \\
\text { Self-improvement }{ }^{17} \\
\text { Intellectual/academic }^{23} \\
\text { Knowledge }^{17} \\
\text { Improved personal appearance }{ }^{10} \\
\text { Moral self-improvement }{ }^{10} \\
\text { General immunities for self }^{10} \\
{ }^{*} \text { Relief from irritations, etc. }{ }^{10}\end{array}$ & $\begin{array}{l}{ }^{*} \text { Maintenance (e.g., happiness, health) }{ }^{13} \\
{ }^{*} \text { Personal: psychological, physical characteristics }{ }^{13} \\
{ }^{*} \text { Physical/psychological benefits for self }{ }^{18,20} \\
\text { General inclusive benefits for self }{ }^{10} \\
\text { Be aggressive }{ }^{21}\end{array}$ \\
\hline Situational & $\begin{array}{l}\text { Specific benefits for parents and relatives }{ }^{10} \\
{ }^{*} \text { Relief from irritations, etc. }{ }^{10}\end{array}$ & ${ }^{*}$ Physical/psychological benefits for self ${ }^{18}$ \\
\hline Situational/IIIness-Related & $\begin{array}{l}\text { No injections }{ }^{21} \\
{ }^{\star} \text { Personal: psychological, physical characteristics }{ }^{23} \\
{ }^{*} \text { Maintenance (i.e., happiness, health) }{ }^{13} \\
\text { Go to school }^{21}\end{array}$ & $\begin{array}{l}{ }^{*} \text { Health and Happiness }{ }^{17} \\
{ }^{*} \text { Physical/psychological benefits for self }{ }^{18} \\
\text { Be cured }{ }^{21} \\
\text { Go home (from the hospital) }{ }^{21}\end{array}$ \\
\hline Altruism & $\begin{array}{l}\text { Altruism }{ }^{13,18,20,22,23} \\
\text { Specific benefits for parents and relatives }{ }^{10} \\
\text { General benefits for parents }{ }^{10}\end{array}$ & $\begin{array}{l}\text { World improvement }{ }^{17} \\
\text { General benefits for others, philanthropies, etc. }{ }^{10}\end{array}$ \\
\hline Fantasy & Fantasy $^{17,23}$ & Supernatural power ${ }^{10}$ \\
\hline Negative & ${ }^{*}$ Miscellaneous ${ }^{11,13,23,24}$ & Not to go to school ${ }^{17}$ \\
\hline No Wishes & ${ }^{*}$ Miscellaneous ${ }^{11,13,23,24}$ & No Wishes ${ }^{17}$ \\
\hline Miscellaneous & $\begin{array}{l}{ }^{*} \text { Miscellaneous }{ }^{11,13,23,24} \\
\text { Idiosyncratic }^{17}\end{array}$ & More Wishes ${ }^{11,13,23,24}$ \\
\hline
\end{tabular}

Previous coding categories are labeled verbatim.

${ }^{*}$ Indicates that previous category has been divided in the current coding system. Two previous investigations ${ }^{12,14}$ not included in the table categorized wishes as abstract versus concrete (although definitions of each were not consistent across studies).

filled out questionnaires while their children were being tested, mailing them in to the investigator in cases in which they were unable to complete them during their child's testing session.

\section{RESULTS}

Analyses of variance were used to compare age, grade, Peabody Picture Vocabulary Test-Revised (PPVT-R), and paternal education across groups. Neither age nor grade differed significantly among the three groups in the sample ( $\mathrm{F}=2.44$ and 1.80 , respectively; $[2,146]$; not significant [NS]). With regard to estimated Verbal IQ, the Duchenne muscular dystrophy (DMD) group (mean PPVT-R standard score $=106.10$ ) was found to differ significantly from the sibling group (mean PPVT-R standard score $=113.91$ ) and the comparison group (mean PPVT-R standard score $=$ 118.26; overall $\mathrm{F}=9.19 ;[2,146] ; p<.001)$. Paternal 
education did not differ significantly between the DMD and sibling groups, although it did differ between the DMD group (mean paternal education $=14.2 \mathrm{yr}$ ) and the comparison group (mean paternal education $=17.1 \mathrm{yr}$; overall $\mathrm{F}=20.12 ;[2,131] ; p<.05)$. With regard to ethnicity, $\chi^{2}$ analyses were used to examine differences in numbers of white versus non-white participants, revealing no significant difference across the three groups $\left(\chi^{2}=4.00\right.$; NS). Gender was not tested, because $100 \%$ of the DMD and comparison groups were male.

The first aim of the study was to develop a reliable scoring system for Three Wishes. To this end, in addition to scoring completed by the first author for the present study, an independent, licensed clinical psychologist scored all wishes on the basis of the category descriptions of the current coding system. This rater was blind to participant group membership. We evaluated interrater reliability using the kappa statistic, computed for wishes from participants of all three groups (total 390 wishes). The kappa statistic for all wishes was $0.81(p=.000)$. Although no standard criteria for acceptable kappa levels currently exist, Fleiss ${ }^{29}$ characterized kappas of 0.40 to 0.60 as fair, 0.60 to 0.75 as good, and greater than 0.75 as excellent. On the basis of these criteria, the Three Wishes coding system's interrater reliability is excellent.

The second aim of the study was to compare wishes of boys with DMD with those of their siblings and of male children in the general population. Percentages of participants who expressed wishes in each of the 13 categories were determined on the basis of the group. Chi-square analyses of the groups' wish percentages were conducted.

In analyses of the DMD group and the sibling group, no significant differences were found in most wish categories, including Situational/Health-Related wishes $\left(\chi^{2}=1.99, \mathrm{~ns}\right)$. The DMD group did make more wishes for Activities $\left(\chi^{2}=4.77 ; p<.05\right)$, fewer Situational wishes $\left(\chi^{2}=8.25\right.$; $p<.01)$, and fewer Miscellaneous wishes $\left(\chi^{2}=4.71\right.$; $p<.05)$ than their siblings. In the remaining nine categories, DMD and sibling wish frequencies did not differ significantly. Analysis of wishes in the DMD and sibling groups is summarized in Table 2.

Similarly, in analyses of the DMD group and the comparison group, no significant differences were found in the frequency of Situational/Health-Related wishes $\left(\chi^{2}=3.45\right.$, NS). However, as when compared with the sibling group, the DMD group made more wishes for Activities than the comparison group $\left(\chi^{2}=7.43 ; p<.01\right)$. In addition, boys with DMD made fewer Future/Goal, Altruism, and Miscellaneous wishes than the boys in the comparison group $\left(\chi^{2}=19.86,20.54\right.$, and $31.90 ; p<$ $.00005, .00005$, and .00001 , respectively). In the remaining eight categories, significant differences between the DMD and the comparison groups were not observed. Analysis of wishes in the DMD and comparison groups is summarized in Table 2.

Finally, for the third study aim, the relationship of wishes to problem child behaviors was examined in the boys with DMD. The DMD group was divided into subgroups on the basis of Child Behavior Checklist (CBCL) Total $t$ scores: Participants with Total $t$ scores equal to or greater than 67 (indicating clinically significant elevation of problem behavior frequency ${ }^{26}$ ) comprised one subgroup $(\mathrm{n}=17)$, and participants with Total $t$ scores less than 67 comprised the other subgroup ( $\mathrm{n}=57)$. These subgroups' wish frequencies were compared with separate $\chi^{2}$ analyses, using the Fisher exact test in cases in which cell values were less than five. Situational/Health-Related wishes in these subgroups did not differ significantly $\left(\chi^{2}=2.83\right.$; NS). However, boys with DMD in the high CBCL Total $t$ score subgroup were more likely to make Interpersonal/Family wishes than their counterparts in the low CBCL Total $t$ score subgroup $\left(\chi^{2}=6.47 ; p<.05\right)$. Frequencies of wishes in the other 12 categories did not differ significantly by CBCL Total $t$ subgroup.

Because boys with DMD have been reported to exhibit high levels of internalizing behaviors, ${ }^{7}$ the relationship of wishes to internalizing behaviors was also examined. The DMD group was divided into subgroups on the basis

Table 2. Chi-Square Analyses of Wishes in Duchenne Muscular Dystrophy versus Sibling and Comparison Groups

\begin{tabular}{|c|c|c|c|c|c|}
\hline Wish Category & $\begin{array}{c}\text { DMD } \\
(n=74) \%\end{array}$ & $\begin{array}{c}\text { Sibling } \\
(n=32) \%\end{array}$ & $\begin{array}{l}\text { DMD-Sibling } \\
x^{2}\end{array}$ & $\begin{array}{c}\text { Comparison } \\
(n=43) \%\end{array}$ & $\begin{array}{l}\text { DMD-Comparison } \\
\qquad X^{2}\end{array}$ \\
\hline Material Goods & 79.73 & 68.75 & 1.49 & 69.77 & 1.48 \\
\hline Pets & 21.62 & 28.13 & 0.52 & 9.30 & 2.91 \\
\hline Activities & 24.32 & 6.25 & $4.77^{\star}$ & 4.65 & $7.43^{\star \star}$ \\
\hline Interpersonal/Family & 5.40 & 6.25 & 0.02 & 11.63 & 1.48 \\
\hline Future/Goal & 4.05 & 6.25 & 0.24 & 34.89 & $19.86^{\star \star \star}$ \\
\hline Personal/Attribute & 0.00 & 3.13 & 2.34 & 4.65 & 3.50 \\
\hline Situational & 2.70 & 18.75 & $8.25^{\star \star}$ & 4.65 & 0.31 \\
\hline Situational/Health-Related & 16.22 & 28.13 & 1.99 & 4.65 & 3.45 \\
\hline Altruism & 2.70 & 3.13 & 0.02 & 32.56 & $20.54^{\star * *}$ \\
\hline Fantasy & 9.46 & 15.63 & 0.85 & 18.61 & 2.04 \\
\hline Negative Wishes & 6.76 & 6.25 & 0.01 & 6.98 & 0.00 \\
\hline No Wishes & 6.76 & 3.13 & 0.55 & 0.00 & 3.04 \\
\hline Miscellaneous & 0.00 & 6.25 & $4.71^{*}$ & 37.21 & $31.90^{\dagger}$ \\
\hline
\end{tabular}

DMD, Duchenne muscular dystrophy.

${ }^{\star} p<.05,{ }^{* *} p<.01,{ }^{* * *} p \leq .00005,{ }^{\dagger} p \leq .00001$. 
of CBCL Internalizing $t$ scores: those with Internalizing $t$ scores $\geq 67$ comprised one subgroup $(\mathrm{n}=18)$, and participants with Internalizing $t$ scores $<67$ comprised the other subgroup $(\mathrm{n}=56)$. These subgroups' wish frequencies were compared with separate $\chi^{2}$ analyses, using the Fisher exact test in cases in which cell values were less than five. Situational/Health-Related wishes in these subgroups did not differ significantly $\left(\chi^{2}=0.63\right.$; NS). However, DMD boys in the high CBCL Internalizing $t$ score subgroup were more likely to make Interpersonal/Family wishes than their counterparts in the low CBCL Internalizing $t$ score subgroup $\left(\chi^{2}=5.90 ; p<.05\right)$. Frequencies of wishes in the other 12 categories did not differ significantly by $\mathrm{CBCL}$ Internalizing $t$ score subgroup.

\section{DISCUSSION}

The present study established a reliable coding system for evaluating Three Wishes. Next, it examined Three Wishes in boys with a chronic illness relative to their siblings and a comparison group of boys. Last, it investigated Three Wishes in boys with Duchenne muscular dystrophy (DMD) in relation to problem child behaviors.

\section{Coding Three Wishes}

Although Three Wishes is often used in clinical settings, little effort has previously been geared toward systematic examination. The present scoring system may be useful in considering Three Wishes presented by individual children in clinical settings, because it provides a simple, operationalized means for evaluating a child's Three Wishes. In addition, this reliable scoring system may be useful in further empirical study of Three Wishes with different groups, such as children with other chronic illnesses and their siblings.

The scoring system is descriptive and parsimonious. Improvements were made on previous coding systems reported, which used as few as two and as many as 27 categories. In addition, the kappa statistic for our system indicates excellent interrater reliability (a demonstrated interrater reliability) never reported in other studies. This likely reflects the robust nature of the scoring system and an inevitable level of error that is inherent to categorizing qualitative data.

\section{Three Wishes in Boys with Duchenne Muscular Dystrophy}

An examination of wish category percentages of boys with DMD and their siblings (Table 2) shows that only $16.25 \%$ of boys with DMD, $28.13 \%$ of their siblings, and $4.65 \%$ of comparison children made health-related wishes. First, it is notable that not all boys with DMD made health-related wishes. This may reflect denial regarding the disease's effects, reluctance to raise such issues, or a level of adjustment or acceptance of this difficult illness. Second, contrary to what was hypothesized, boys with DMD did not make significantly more health-related wishes than their siblings or the comparison boys. On the surface, this indicates that the boys with DMD are not overly preoccupied with their physical state and may well reflect good adjustment to the disease. This school-age sample may not yet be as concerned with their health as their older counterparts, because the symptoms of DMD become most debilitating during adolescence and young adulthood. Third, health-related wishes were not associated with increased behavior problems, suggesting that these wishes are not an indicator of decreased psychological functioning.

In examining Three Wishes of boys with DMD compared with their siblings and healthy unrelated boys, a significant difference emerged for both analyses: Boys with DMD made more Activities wishes than either the sibling or comparison group. Because wishes coded in this category are not those directly limited by the child's illness, they represent realistic desires that could be attained even with limited mobility. For example, wishes to go to Disney World reflect a desired end that is possible, whereas wishes to ride a bike do not. It is possible that boys making these wishes long for activities as a feasible way in which to enhance their lives. It also may be that the additional financial, emotional, and logistical requirements this disease places on a family make activities less accessible or perhaps simply place a sense of burden around such activities. In either event, these wishes are realistic, possible events and may suggest a realistic outlook for increasing the quality of life.

In contrast, boys with DMD made significantly fewer Situational wishes than their siblings. This category represents wishes for changes in the child's own personal situation, such as "that my parents would get back together" or "that I would have more friends." The significantly lower frequency of these wishes observed in the DMD group may be related to the weaker interpersonal or social skills noted in other research from our group. ${ }^{8}$ Because boys with DMD generally exhibit poorer social abilities, they may not be as focused on such Situational wishes as their siblings or as boys in general.

Relative to the comparison group, but not their siblings, boys with DMD made fewer future- or goal-related wishes, likely reflecting an altered perspective a child with this disease may develop. This finding indicates that families with DMD focus more on the "here-and-now," which may be an adaptive response in a family with a child with a shortened life expectancy. Similarly, boys with DMD made fewer altruistic wishes than comparison children, suggesting a focus on the immediate rather than the "bigger picture." Interestingly, siblings were also found to make fewer Future/Goal wishes than the comparison group $\left(\chi^{2}=9.01 ; p<.005\right)$, perhaps suggesting a more presentfocused perspective for all family members. In addition, it may be that higher paternal education level observed in the comparison group contributes to the differences in this wish type; the boys in the comparison group may come from families with higher expectations for education or career goals.

Both the sibling and comparison groups made significantly more Miscellaneous wishes than the DMD group. Inspection of wishes coded in this category indicates that they were primarily for "more wishes." Perhaps the focus 
on attainable wishes, as observed in the finding of greater Activities wishes in the DMD group, contributes to this finding as well. If boys with DMD focus their attention on wishes for possible events, such as attainable activities that would enhance their daily life and happiness, perhaps they are unlikely to wish for something fantastical.

\section{Three Wishes and Psychological Functioning in Boys with Duchenne Muscular Dystrophy}

As Three Wishes is often used clinically to understand a child's experience, and is hypothesized to reflect the psychological state of a child, evaluation of Three Wishes with a measure of psychological functioning was undertaken. In particular, the relationships between elevated Child Behavior Checklist (CBCL) Total and Internalizing $t$ scores and wishes were examined. Again, the hypothesis that health-related wishes were associated with increased behavioral distress was not supported. Rather, for the DMD group, a relationship between wish type and elevated child problem behaviors was found only for Interpersonal/Family wishes, in that boys with high Total or Internalizing $t$ scores were more likely to express these wishes. Perhaps this finding reflects the social isolation and poor interpersonal skills noted by other investigators. It may be that the boys with DMD sense their relative isolation but do not have the skills to remedy it. As these boys make the more general Interpersonal/Family wishes, rather than the situationspecific wishes that address negative personal circumstances, they may reflect a more basic means of expressing such wishes for interpersonal changes. This increased focus on general family functioning may be a conduit to relief of distress associated with this fatal illness for boys with DMD at their level of functioning.

Overall, the present data indicate the striking similarity of Three Wishes across the three groups studied. Contrary to the hypotheses, and to clinical wisdom, the DMD groups' wishes with health-related themes, commonly believed to be indicative of underlying issues, were neither increased relative to sibling or comparison groups nor related to parent report of child-behavior problems. This suggests that Three Wishes does not detect psychological maladjustment in the DMD group, because these children are relatively well adjusted. Although $24 \%$ of boys with DMD had elevated CBCL Internalizing $t$ scores, our research has shown that these scores are primarily the result of elevations in the Social Problems scale and has indicated that it is a part of the phenotype rather than a reaction to the illness. ${ }^{8}$ In particular, boys with DMD have been found to exhibit greater social problems than another sample of medically ill children, those with cerebral palsy, a disease that also leads to both cognitive and motor impairments. $^{8}$ In further support of the present findings, a $t$ test comparing the mean $t$ score of a subset of the DMD participants in this study $(\mathrm{n}=36)$ and their siblings ( $\mathrm{n}=17)$ who completed the Childhood Depression Inventory, ${ }^{30}$ a self-report questionnaire, was not significant. In addition, the DMD children did not generally rate themselves as depressed (mean $t$ score $=46.22$ ). Together, these findings underscore the tenet that boys with DMD, in not focusing on their illness, are more like healthy children than unlike them. Although their conception of and concern with their disease may change over time, the age group studied did not present wishes that were more health-focused than other children's.

There are limitations to generalization of the present findings that must be considered. First, replication of this new category system with other samples would provide further support for its usage. Participants of the present study were experiencing one particular stressor. Future examination of Three Wishes might focus on the relationship between psychiatric symptoms or diagnosis and the wishes children express. Such an investigation may further establish the ways in which Three Wishes may be a useful clinical tool for assessing a child's psychological experience.

Second, the present sample may exhibit the effects of a selection bias, in that those families who responded positively to recruitment efforts may be those who are coping relatively well with the emotional and practical effects of DMD. Such a bias would likely have an effect on the data presented here, in that CBCL reports and Three Wishes may be relatively more positive than in the DMD population at large. Unfortunately, it is not possible to measure the extent to which the present samples of boys with DMD and their siblings are representative of the larger populations from which they are drawn in this regard.

A final factor to be considered is the relative homogeneity of the male comparison group. These participants were fairly similar with regard to ethnicity, estimated Verbal IQ, and paternal education, the latter two of which were higher than average. These factors may have had an effect on the comparison boys' experiences compared with the other groups and therefore may have influenced their Three Wishes. This relative lack of diversity in the comparison group should be improved in future research. However, the consideration the comparison group is given in the present study is a notable contrast to existing literature in Three Wishes and other projective techniques, which generally do not include comparison groups, and is a recommended approach to future examinations of projective techniques.

In summary, our data indicate that boys with DMD do not offer health-related wishes when given an open-ended question to express their desires. Whether this is because of reluctance to self-disclose, adjustment and acceptance of this life condition, or a still-developing understanding of the consequences of the illness is unclear. However, given that no relationship was found between increased behavior problems and health-related wishes among the boys with DMD, and that few significant differences were found across groups in wish type, these data support the idea that boys with DMD are more like their healthy peers than they are different, and that the nature of their wish content reflects appropriate developmental desires rather than illness-focused ones.

Acknowledgments. We extend our appreciation to the children and parents who participated in this study. Further, we thank Alice E. Sohn, Ph.D., for her assistance. This work was supported by grants from the National Institute of Child Health and Human Development (R29 HD34155) and the Muscular Dystrophy Association to V.J.H. 


\section{REFERENCES}

1. Hinton VJ, DeVivo DC, Nereo NE, Goldstein E, Stern Y. Poor verbal working memory across intellectual level in boys with Duchenne muscular dystrophy. Neurology. 2000;13:2127-2132.

2. Hinton VJ, DeVivo DC, Nereo NE, Goldstein E, Stern Y. Selective deficits in verbal working memory associated with a known genetic etiology: the neuropsychological profile of Duchenne muscular dystrophy. J Int Neuropsychol Soc. 2001;7:45-54.

3. Truit CL. Personal and social adjustments of children with muscular dystrophy. Clin Psychol. 1954;124-128.

4. Sherwin AC, McCully RS. Reactions observed in boys of various ages (ten to fourteen) to a crippling, progressive and fatal illness (muscular dystrophy). J Chronic Dis. 1959;13:59-68.

5. Fitzpatrick C, Barry C, Garvey C. Psychiatric disorder among boys with Duchenne muscular dystrophy. Dev Med Child Neurol. 1986;28: $589-595$.

6. Harper DC. Personality correlates and degree of impairment in male adolescents with progressive and nonprogressive physical disorders. J Clin Psychol. 1983;39:859-867.

7. Thompson RJ Jr, Zeman JL, Fanurik D, Sirotkin-Roses M. The role of parent functioning and coping and family functioning in parent and child adjustment to Duchenne muscular dystrophy. J Clin Psychol. 1992;48:11 - 19 .

8. Hinton VJ, Fee R. Evidence of poor social skills among boys with Duchenne muscular dystrophy. Paper presented at: The 33rd Annual Gatlinburg Conference on Research and Theory in Mental Retardation and Developmental Disabilities; March 2000; San Diego, CA.

9. Washburne JN: The impulsions of adolescents as revealed by their written wishes. J Juv Res. 1932;16:193-212.

10. Jersild AT, Markey FV, Jersild CL. Children's fears, wishes, daydreams, likes, dislikes, pleasant and unpleasant memories. Child Dev Monogr. 1932;12:57-59.

11. Ables B. The three wishes of latency age children. Dev Psychol. 1972;6:186.

12. Brook JS, Gordon S. Wishes of adolescents. Psychol Rep. 1979;44: $593-594$.

13. Horrocks JE, Mussman MC. Developmental trends in wishes, confidence, and the sense of personal control from childhood to middle maturity. J Psychol. 1973;84:241-252.
14. Milgram NA, Riedel WW. Developmental and experiential factors in making wishes. Child Dev. 1969;40:763-771.

15. Wheeler DK. Expressed wishes of students. J Genet Psychol. 1963; 102:75-81.

16. Cobb HV. Role-Wishes and general wishes of children and adolescents. Child Dev. 1954;25:161-171.

17. Guarnaccia VJ, Vane JR. Children's wishes. J Sch Psychol. 1979;17: $126-131$.

18. Vandenwiele M. Wishes of adolescents in Senegal. Psychol Rep. 1981;48:695-698

19. Jersild AT. Children's wishes, dreams, fears, daydreams, pleasant and unpleasant memories. Psychol Bull. 1933;30:552-553.

20. Wilson FT. Expressed wishes of children and college women students. J Psychol. 1938;5:91-105.

21. Martinson IM, Liu BY. Three wishes of children with cancer. Int Nurs Rev. 1988;35:143-146.

22. Chiu JP, Nevius JR. Three wishes of gifted and nongifted adolescents. J Genet Psychol. 1990;151:133-138.

23. Karnes FA, Wherry JN. Wishes of fourth- through seventh-grade gifted students. Psychol Sch. 1981;18:235-239.

24. Kokonis ND. Three wishes of Black American children: psychosocial implications. Percept Mot Skills. 1974;38:1135-1138.

25. Winker JB. Age trends and sex differences in the wishes, identifications, activities and fears of children. Child Dev. 1949;20: $191-200$.

26. Achenbach TM. Manual for the Child Behavior Checklist/4-18 and 1991 Profile. Burlington, VT: University of Vermont Department of Psychiatry; 1991.

27. Dunn LM, Dunn LM. The Peabody Picture Vocabulary Test Revised: Manual for Forms $L \&$ M. Circle Pines, MN: American Guidance Service; 1981.

28. Dunn LM, Dunn LM. Examiner's Manual for the Peabody Picture Vocabulary Test. 3rd ed. Circle Pines, MN, American Guidance Service, 1997.

29. Fleiss J. Statistical Methods for Rates and Proportions. New York, NY: Wiley; 1981.

30. Kovacs M. Childhood Depression Inventory. North Tonawonda, NY: Multi-Health Systems; 1992. 


\section{AUTHOR QUERIES}

\section{AUTHOR PLEASE ANSWER ALL THE QUERIES}

AQ1 = Ref 9: could not locate article. Please confirm reference information including journal abbreviation.

AQ2 = Are exact values needed in \% columns? Journal style rounds off percentages: 79.73 to 80 etc.

\section{END OF AUTHOR QUERIES}

